\title{
PEMBANGUNAN PELINGGIH SURYA
}

\author{
I Made Diana \\ Program Studi Arsitektur,Fakultas Teknik,Universitas Dwijendra \\ Gerhana263@gmail.com \\ Desak Made Sukma Widiyani,ST, MT. \\ Program Studi Arsitektur,Fakultas Teknik,Universitas Dwijendra \\ sukmawidiyani@gmail.com
}

\begin{abstract}
Abstrak
Pada dasarnya pulau bali mempunyai banyak kebudayaan,adat istiadat,kebiasaan-keiasaan yang berbeda disetiap wilayah mengikuti desa kala patra. Akan tetapi ada banyak hal yang tidak bisa lepas dan mempunyai ikatan serta merupakan sebuah keharusan bagi masyarakat bali khususnya yang beragama hindu yaitu mempunyai tempat suci di masing-masing rumah yang disebut merajan (pelinggih).dan dilengkapi dengan pelinggih surya yang merupakan stana dari bhatara surya atau siwa raditya yang menjaga kestabilan dan keseimbangan pekarangan rumah biasanya berbentuk padma yang berada ditengah natah rumah yang pada umumnya dibali disebut; Pelinggih pengijeng karang/ sebagai penjaga (Surya natah/ yang menyinari). Pelinggih Surya ini sebagai simbolis yang digunakan untuk menghaturkan sesaji yang dipersembahkan kepada Betara surya(dewa matahari) sang hyang surya/siwa raditya sebagai saksi segala kegiatan manusia khususnya spiritual( yadnya). Sistem pemujaan dewa matahari disebut surya sewana dilakukan pada waktu matahari terbit dan matahari terbenam menjadi ciri penganut sekta sora. Setiap ritual agama dibali selalu dilakukan pemujaan terhadap dewa surya sebagai dewa yang memberikan persaksian bahwa seorang telah melakukan yadnya busana(wastra)yang digunakan dalam pelinggih surya yaitu;kain berwarna putih sebagai simbul kesucian,Bebantenan (upakara) yang dipersembahkan di pelinggih surya yaitu; tegteg daksina dan runtutanya canang ketipat kelanan. Dalam hal pembangunan tempat suci kita sebagai warga masyarakat bali yang beragama hindu khususnya mempunyai tanggung jawab serta kewajiban untuk menjaga, melestarikan dan mempertahankan nilai-nilai dan norma adat isitiadat bali yang merupakan kebudayaan dan warisan leluhur dari generasi ke generasi. Dan untuk lebih memahami tentang arti dan fungsi dari keberadaan pelinggih surya tentunya kita sebagai generasi harus mencari iformasi yang akurat mengenai pelinggih surya yaitu dengan mencari literatur,melukan observasi serta melakukan perbandingan dibeberapa tempat,dan mencari penjelasan kepada yang berkompeten dan dapat dipercaya dalam permasalahan ini seperti, Pedanda,Undagi,Tukang Banten dll.
\end{abstract}

Kata Kunci: Pembangunan, Pelinggih Surya, Bali

\begin{abstract}
Basically the island of Bali has many cultures, customs, habits that are different in each region following the Kala Patra village. However, there are many things that cannot be separated and have ties and it is a must for Balinese people, especially those who are Hindus, namely having a holy place in each house called merajan (pelinggih). And equipped with a solar pelinggih which is the stana of the solar bhatara. or siwa raditya who maintains the stability and balance of the house yard, usually in the form of a lotus in the middle of the house's natah which is generally called bali; Pelinggih pengijeng coral / as a guard (Surya natah / who shines). This pelinggih is symbolic to make offerings offered to betara surya (sun god) the hyang surya / siwa raditya as a witness to all human activities, especially spiritual (yadnya). The system of worshiping the sun god, called surya sewana, is performed at sunrise and sunset, which characterizes followers of the Sora sect. Every religious ritual in Bali is always worshiped by the god of the sun as a god who testifies that someone has done the yadnya clothes (wastra) used in the solar pelinggih, namely; white cloth as a symbol of purity, Bebantenan (upakara) which is offered on the pelinggih of the sun, namely; Tegteg Daksina and its runtutanya tapered off.

In terms of the construction of sacred places, we as Balinese citizens who are Hindu in particular have the responsibility and obligation to maintain, preserve and maintain the values and norms of Balinese customs, which are culture and ancestral heritage from generation to generation. And to better understand the meaning and function of the existence of the solar pelinggih, of course we as a generation must look for accurate information about the solar pelinggih, namely by looking for literature, making observations and making comparisons in several places, and looking for
\end{abstract}


explanations to those who are competent and reliable in this problem such as Pedanda, Undagi, Tukang Banten etc.

Keyword: Contruction, Pelinggih Surya, Bali

\section{PENDAHULUAN}

Dalam perkembangan jaman seperti saat ini yang begitu pesat dalam segala bidang,tanpa kita sadari banyak nilai-nilai kebudayaan yang kita miliki mulai bergeser mengikuti perkembangan dan jaman secara nasional, sehingga berdampak pada pemahaman generasi tentang keberadaan,fungsi serta filosofi yang berkaitan dengan kebudayaan serta keagamaan,yaitu tempat suci, Salah satu nya adalah keberadaan dan fungsi dari pelinggih surya.Oleh sebab itu kita sebagai generasi mempunyai kewajiban untuk mempertahankan dan menjaga serta mencari pemahaman melalui literatur,ataupun orang yang berkompeten seperti pedanda,undagi dll, sehingga kita bisa mendapatkan informasi sebagai bahan untuk mempelajari agar mengetahui tentang filosofi,fungsi dan keberadaan pelinggih surya. Hal ini merupakan tanggung jawab bersama sebagai warga masyarakat bali yang beragama hindu khususnya mempunyai kewajiban untuk menjaga, melestarikan dan mempertahankan nilainilai dan norma adat istiadat bali yang merupakan kebudayaan dan warisan leluhur dari generasi ke generasi. Dilihat dari keberadaan masyarakat bali saat ini sedang mengalami penurunan pemahaman tentang arti,bentuk nama serta fungsi dari beberapa tempat suci yang ada di sekeliling kita bahkan di area rumah sendiri. Dalam tugas ini saya akan mengangkat salah satu bangunan tempat suci yang ada di pekarangan rumah yaitu: PELINGGIH SURYA.dengan tujuan agar kita sebagai masyarakat bali khususnya agama hindu lebih memahami tentang filosofi,arti,fungsi dan penempatan pelinggih surya pada pekarangan rumah(natah).

Studi tentang bangunan pelinggih surya di lakukan guna lebih mendalami lagi sebagian dari ilmu pengetahuan arsitektur traditional Bali yang mendekati kebenaran, sehingga arah pengemangan nilai luhur yang tinggi dari warisan nenek moyang kita menjadi kokoh dan kuat, dan juga dapat diungkapkan untuk menambah pembendaharaan kebudayaan bangsa sebagai salah satu bahan informasi dan gambaran yang menyeluruh bagi masyarakat Bali khususnya dan bangsa Indonesia pada umumnya.

Pelinggih Surya merupakan stana dari bhatara surya atau siwa raditya yang menjaga kestabilan dan keseimbangan pekarangan rumah biasanya berbentuk padma sari sebagai simbolis yang digunakan untuk menghaturkan sesaji yang dipersembahkan kepada betara surya(dewa matahari) sang hyang surya/siwa raditya sebagai saksi segala kegiatan manusia khususnya spiritual( yadnya). Pelinggih surya juga merupakan salah satu bangunan pelinggih yang wajib ada dalam setiap pekarangan rumah yang terletak di natah sebagai simbul dari tempat linggih dewa surya yang tak lain merupakan dewa matahari dalam kepercayaan pemeluk agama hindu di bali. Keberadaan pelinggih surya bisa dibilang merupakan salah satu bentuk pengabdian masyarakat hindu bali kepada dewa surya yang merupakan dewa dari segala sumber kehidupan yang berperan sebagai dewa matahari yang memberikan sinar setiap hari sehingga manusia bisa beraktivitas dengan normal. Dalam pembangunan surya menggunakan konsep arah mata angin dan hulu teben yang dimana penempatan pelinggih surya menghadap ke arah barat agar pada saat kita melakukan persembahyangan menghadap ke hulu yang mana lumbrahya orang melakukan persembahyangan menghadap kearah timur ataupun utara yang dijadikan hulu atau luanan.

\subsection{Permasalah Penelitian}

Adanya perbedaan jenis bentuk bangunan surya sesuai desa kala patra dimana tempat itu berada maka perlu adanya studi khusus tentang bangunan surya yang nanti bisa dipakai sebagai bahan pertimbangan di dalam perencanaan atau pembuatan bangunan pelinggih surya 


\subsection{Wawasan Dan Rencana Pemecahan}

Dalam pembangunan surya natah harus sesuai dengan desa kala patra dimana pelinggih itu dibangun agar tidak menyimpang dengan aturan adat dan buadaya serta kebiasaankebiasaan yang ada di tempat tersebut

\subsection{Rumusan Masalah}

a. Apa nilai nilai pilosofi yang melatar belakangi pembangunan pelinggih surya?

b. Bagaimana fungsi,bentuk dan makna dari pelinggih surya dikaitkan dengan aktivitas sosial budaya masyarakat hindu bali?

c. Bagaimana proses pembangunan pelinggih surya di bali?

\subsection{Tujuan}

a. Untuk mengetahui apa nilai nilai filosofi yang melatar belakangi pembangunan pelinggih surya

b. Untuk mengetahui apa fungsi,bentuk dan makna dari pelinggih surya dikaitkan dengan aktivitas sosial budaya masyarakat dibali

c. Untuk mengetahui proses pembangunan pelinggih surya

\section{METODE}

1.Pencarian data

Dalam pengumpulan data-data yang dapat mendukung penulisan ini, menggunakan beberapa teknik yaitu :

a. Studi literature yaitu dengan memilih data-data literatur yang ada kaitannya dengan permasalahan yang ada.

b. Observasi yaitu dengan cara mengadakan pengamatan langsung ke lapangan dengan mengambil beberapa sample yang nantinya dapat dipakai perbandingan di dalam perancangan.

c. Wawancara yaitu dengan melakukan wawancara langsung dengan orang yang berkompeten dan dapat dipercaya dalam permasalahan ini seperti, Pedanda, Undagi, Tukang banten dll.

\section{Analisa data}

Setelah melakukan pengumpulan data melalui literatur,observasi dan melakukan wawancara langsung maka dapat dituangkan dalam data yang nantinya menjadi informasi baru agar karakteristik data menjadi lebih mudah dimengerti dan berguna untuk solusi suatu permasalahan yang ditemukan dilapangan.

3.Penarikan kesimpulan

Setelah melakukan analisa data maka selanjutnya membuat sebuah kesimpulan dengan menterjemahkan inti pokok permasalahan yang telah dibahas dari beberapa data yang didapatkan melalui literatur,observasi dan wawancara.

\section{HASIL DAN PEMBAHASAN}

Pelinggih (sanggah) Surya merupakan stana dari bhatara surya atau siwa raditya yang menjaga kestabilan dan keseimbangan pekarangan rumah biasanya berbentuk padma yang berada ditengah natah rumah yang pada umumnya dibali disebut;Pelinggih pengijeng karang/ sebagai penjaga(Surya natah/ yang menyinari)

Pelinggih ini sebagai simbolis yang digunakan untuk menghaturkan sesaji yang dipersembahkan kepada betara surya(dewa matahari) sang hyang surya/siwa raditya sebagai saksi segala kegiatan manusia khususnya spiritual( yadnya).Sistem pemujaan dewa matahari disebut surya sewana dilakukan pada waktu matahari terbit dan matahari terbenam menjadi ciri penganut sekta sora. 
Setiap ritual agama dibali selalu dilakukan pemujaan terhadap dewa surya sebagai dewa yang memberikan persaksian bahwa seorang telah melakukan yadnya.busana(wastra)yang digunakan dalam pelinggih surya yaitu;kain berwarna putih sebagai simbul kesucian.Bebantenan (upakara) yang dipersembahkan dipelinggih surya yaitu; tegteg daksina dan runtutanya canang ketipat kelanan. Bukti dari kristalisasi sekte ini dalam siwa siddhanta yang masih kita dapat liat yaitu penggunaan sebuah mantra yang mengagungkan dewa siwa raditya dalam kramaning sembah.

Pelinggih surya merupakan salah satu bangunan pelinggih yang wajib ada dalam setiap pekarangan rumah yang terletak di natah sebagai simbul dari tempat linggih dewa surya yang tak lain merupakan dewa matahari dalam kepercayaan pemeluk agama hindu di bali. Keberadaan pelinggih surya bisa dibilang merupakan salah satu bentuk pengabdian masyarakat hindu bali kepada dewa surya yang merupakan dewa dari segala sumber kehidupan yang berperan sebagai dewa matahari yang memberikan sinar setiap hari sehingga manusia bisa beraktivitas dengan normal. Dalam pembangunan surya menggunakan konsep arah mata angin dan hulu teben yang dimana penempatan pelinggih surya menghadap kearah barat agar pada saat kita melakukan persembahyangan menghadap ke hulu yang mana lumbrahya orang melakukan persembahyangan menghadap kearah timur ataupun utara yang dijadikan hulu atau luanan.

Adapun beberapa landasan tata ruang, tata letak, dan tata bangunan yaitu dapat dibagi dalam :

a. Keseimbangan alam. Wujud perumahan umat Hindu bentuk keseimbangan antara alam Dewa, alam manusia dana lam Bhuta yang diwujudkan dalam satu perumahan terdapat tempat pemujaan, tempat tinggal dan pekarangan dengan penunggu karangnya yang dikenal dengan istilah Tri Hita Karana.

b. Rwa bhineda, Hulu Teben, Purusa pradhana. Rue Bhinedha diwujudkan dengan bentuk Hulu Teben ( hilir ). Yang dimaksud dengan hulu adalah arah atau terbit matahari, arah gunung dana rah jalan raya ( margi agung ). Perwujudan purusa perdhana adalah dalam bentuk penyediaan natar. Sebagai ruang yang merupakan pertemuan antara akasa dan pertiwi.

c. Tri Angga dan Tri Mandala. Pekerangan Rumah Umat Hindu secara garis besar di bagi menjadi 3 bagian ( tri mandala ) yaitu utama mandala untuk penempatan bangunan yang bernilai utama seperti, tempat pemujaan. Madya mandala untuk penempatan bangunan yang bernilai madya yaitu tempat tinggal penghuni. Dan nista mandala untuk penempatan bangunan yang bernilai nista yaitu, kandang babi atau sapi. Secara vertical masing - masing bangunan dibagi menjadi 3 bagian ( tri angga ) yaitu utama angga adalah atap, madya angga adalah badan bangunan yang terdiri dari tiang dan dinding, serta nista angga adalah batur atau pondasi.

d. Harmonisasi dengan potensi lingkungan. Harmonisasi dengan lingkungan di wujudkan dengan memanfaatkan potensi setempat seperti, bahan bangunan dan prinsip-prinsip bangunan Hindu.

Dalam ajaran Asta Kosala - Kosali dan Asta Bhumi kaidah rancangan bangunan pelinggih surya sebagai stana dewa matahari yang memberi kehidupan pada setiap ciptaan tuhan dan sebagai saksi dari setiap kegiatan manusia.

Dalam arsitektur Bali mengandung filosofi symbol dari Bhuana Agung dengan Trilokanya, ( sumber : Asta Kosali Ny. Gd. Bendesa K. Tonjaya ) yaitu :

- Bhur Loka ( alam bhuta / hewan )

- Bwas Loka ( alam manusia )

- Swah Loka ( alam dewa )

Sedangkan dalam bhuana Alit ( badan manusia ) juga di bagi 3 bagian, disebut " Tri Angga ":

- Nistama Angga ( kaki )

- Madya Angga ( badan )

- Utama Angga ( kepala ) 
Arsitektur bali mengikuti konsep Bhuana Agung dengan pembagian menjadi 3 bagian, dan memiliki hitungan ganjil seperti 1,3,5,7,9, dan seterusnya. Bangunan itu sendiri merupakan symbol dari Bhuana Agung dengan Trilokanya, yaitu :

- Pondasi dan lantai sebagai kaki ( Bhur Loka )

- Konstruksi Vertikal ( pasangan bataran ) sebagai badan ( Bwas Loka )

- Rong atau atap sebagai kepala ( Swah Loka )

Dasar-dasar yang digunakan dalam bangunan pelinggih surya yakni menggunakan petunjukpetunjuk lontar Asta Kosala-Kosali dan Asta Bumi. Adapun ukuran - ukuran dasar yang di gunakan berdasarkan ukuran tubuh si pemilik, Pelinggih surya pada umumnya berbentuk padmasari. Sebagaimana halnya proses pembangunan pada bangunan Tradisional Bali pada umumnya, proses pembangunan pelinggih surya juga harus melalui proses dan upacara mulai dari persiapan sampai selesai.

Dalam proses persiapan ada beberapa tahap yang harus dilaksanakan yaitu untuk menentukan gegulak, yang diambil adalah orang yang dituakan didalam suatu keluarga sebagai pemilik pelinggih surya yang akan dibangun. Dalam pembuatan gegulak harus melalui upacara pembuatan gegulak terlebih dahulu. Sesudah bahan-bahan dipersiapkan, lalu pada tahap selanjutnya adalah tahap pengerjaan, yang dimulai dari pengerjaan bagian bawah yaitu bataran sampai pada rongan.

a. Pengerjaan bagian bawah atau batarannya.

Pada bagian bataran terdapat tepas hujan, bataran dan undag yang sudah diperhitungkan dimensinya pada saat perencanaan. Sebelum pemasangan tepas hujan dan batarannya terlebih dahulu ada beberapa tahap proses dan upacara yang dilaksanakan mulai dari

1) Proses upacara nyukat, yang bertujuan untuk menentukan posisi surya yang akan dibangun, serta denah dimensi surya.

2) Proses dan upacara ngruak, yang bertujuan membersihkan lahan yang akan dibangun dan sekaligus membuat lubang pondasi sesuai dengan sukat.

3) Proses dan upacara nasarin, yaitu peletakan batu pertama pada bangunan yang menggunakan sarana upacara.

Setelah proses upacara nasarin selesai baru dilanjutkan dengan proses pengerjaan batarannya. Setelah pelinggih surya selesai secara keseluruhan, sebelum diupacarai, terlebih dahulu dibersihkan secara fisik yang disebut dengan ngeresikin. Setelah benar-benar bersih, baru dibuatkan upacara terakhir yaitu melaspas.

Adapun bentuk pelinggih surya natah yaitu sebagai berikut:

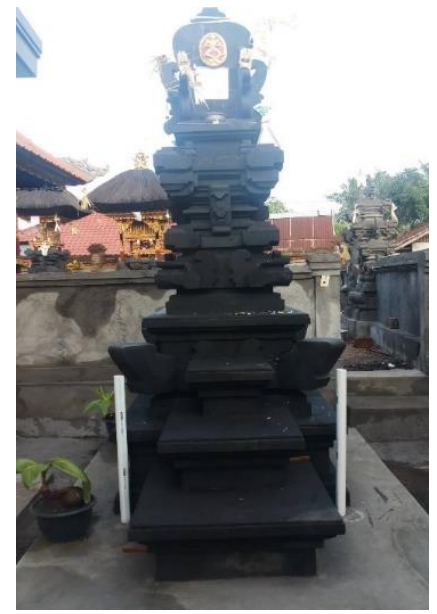

Gambar:1. Tampak depan pelinggih surya br.kedua desa baha

( Sumber : studi lapangan ) 


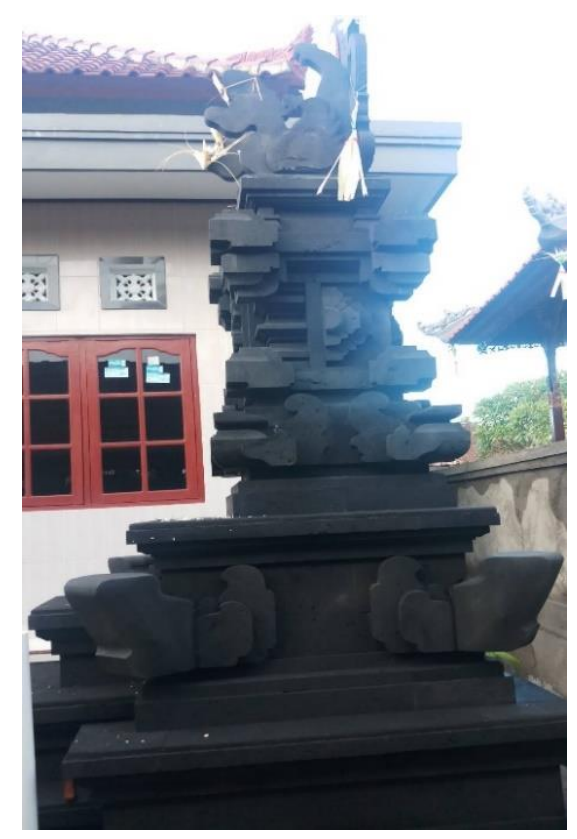

Gambar 2. photo tampak samping pelinggih surya br.kedua,desa baha ( Sumber : studi lapangan)

\section{PENUTUP}

\section{Kesimpulan}

Dari pembahasan diatas maka dapat disimpulkan bahawa Pelinggih Surya merupakan stana dari bhatara surya atau siwa raditya yang menjaga kestabilan dan keseimbangan pekarangan rumah biasanya berbentuk padma yang berada ditengah natah rumah yang pada umumnya dibali disebut;Pelinggih pengijeng karang/ sebagai penjaga(Surya natah/ yang menyinari).Pelinggih surya sebagai simbolis yang digunakan untuk menghaturkan sesaji yang dipersembahkan kepada betara surya(dewa matahari) sang hyang surya/siwa raditya sebagai saksi segala kegiatan manusia khususnya spiritual( yadnya). Setiap ritual agama dibali selalu dilakukan pemujaan terhadap dewa surya sebagai dewa yang memberikan persaksian bahwa seorang telah melakukan yadnya. Dalam ajaran Asta Kosala - Kosali dan Asta Bhumi kaidah rancangan bangunan pelinggih surya sebagai stana dewa matahari yang memberi kehidupan pada setiap ciptaan tuhan dan sebagai saksi dari setiap kegiatan manusia. Dasar-dasar yang digunakan dalam bangunan pelinggih surya yakni menggunakan petunjuk-petunjuk lontar Asta Kosala-Kosali dan Asta Bumi. Adapun ukuran - ukuran dasar yang di gunakan berdasarkan ukuran tubuh si pemilik, Pelinggih surya pada umumnya berbentuk padmasari. Sebagaimana halnya proses pembangunan pada bangunan Tradisional Bali pada umumnya, proses pembangunan pelinggih surya juga harus melalui proses dan upacara mulai dari persiapan sampai selesai.diantaranya nyukat,ngeruak,nasarin,mereresik dan yang terakhir melaspas.

\section{DAFTAR PUSTAKA}

Babad Bali. 2014. Asta Kosala - Kosali. Tersedia pada http://www.babadbali.com/.

Bappeda tingkat I Bali dan Universitas Udayana. 1982, Pengembangan Arsitektur Tradisional Bali untuk Keserasian Alam Lingkungan, Sikap Hidup, Tradis dan Teknologi. Denpasar: Bappeda Tingkat I Bali. 
Dwijendra. N. K. Acwin 2008. Arsitektur Rumah Tradisional Bali, Udayana University Press, halaman: 121.

Dwijendra. N. K. Acwin 2009. Arsitektur \& Kebudayaan Bali Kuno: Udayan University Press; Denpasar Bali.

Gelebet, I Nyoman. Dkk. 1986. Arsitektur Tradisional Daerah Bali. Denpasar.Departemen Pendidikan dan Kebudayaan Proyek Inventarisasi dan Dokumen Kebudayaan Daerah.

Gelebet, I Nyoman. 1984. Arsitektur Rumah Tradisional Bali. Penerbit Departemen Pendidikan Dan Kebudayaan. 